\title{
Volatile anesthetic sevoflurane suppresses lung cancer cells and miRNA interference in lung cancer cells
}

This article was published in the following Dove Press journal:

OncoTargets and Therapy

\author{
Le Wang \\ Tiao Wang \\ Jia-Qi Gu \\ Hui-Bin Su \\ Department of Anesthesiology, \\ The Affiliated Suzhou Hospital of \\ Nanjing Medical University, Suzhou, \\ 215000 , China
}

Correspondence: Hui-Bin Su Department of Anesthesiology, The Affiliated Suzhou Hospital of Nanjing Medical University, Baita West Road I6, Suzhou, Jiangsu, 215000, China

Tel +86 I3205I9 9786

Email sudamazui@I26.com
Purpose: Sevoflurane is widely used in lung cancer surgery. It is well known that volatile anesthetics have a lung-protective effect in lung cancer surgery. However, the association between the inhibition of cancer cells and miRNAs interference remains unknown. Whether sevoflurane can affect some miRNAs in A549 cells has not been reported. The main aim of the present study was to investigate the effect of 3\% sevoflurane on A549 cells and assess whether it regulates A549 cells by interfering with miRNA.

Methods: In three percent sevoflurane-pretreated A549 cells, treated for a duration of 30 minutes, the apoptosis rate of A549 cells was evaluated using a flow cytometer. The expression of 6 types of miRNAs associated with non-small cell lung cancer was analyzed by real-time quantitative polymerase chain reaction.

Results: An obvious apoptosis-promoting effect was found in A549 cells, which had been treated with $3 \%$ sevoflurane. The expression of several miRNAs that regulate apoptosis was significantly changed compared with the control group.

Conclusion: Three percent sevoflurane can significantly increase the apoptosis rate of A549 cells, which may reduce the spread of cancer cells caused by operation. Sevoflurane disturbed the expression of the miRNAs that regulate apoptosis.

Keywords: sevoflurane, miRNAs, apoptosis

\section{Introduction}

Non-small cell lung cancer (NSCLC) is a serious threat to the health of all mankind and accounts for $\sim 80 \%$ of all lung cancers. ${ }^{1}$ Surgical resection is a common treatment for NSCLC, but surgery cannot completely prevent tumor proliferation, and it also has some adverse effects on tumor cells. ${ }^{2}$

The effects of anesthetics and anesthesia techniques can possibly affect the longterm outcome of patients who have undergone cancer surgery. ${ }^{3}$ The volatile anesthetic sevoflurane is widely used in surgery as there is extensive clinical data supporting its safety. ${ }^{4}$ Over the years, there has been a growing interest in the biological effects of sevoflurane on tumor and organ systems and the molecular mechanisms involved. The antiproliferative and anti-invasive effects of sevoflurane have been demonstrated on some cancer cells. ${ }^{5,6}$

miRNA is estimated to control $30 \%-90 \%$ of human genes. ${ }^{7}$ miRNA has a specific expression profile in lung cancer and participates in the whole process of lung cancer development. ${ }^{8}$

In a previous study, it was found that sevoflurane affects the expression of miRNAs in normal rat lung. ${ }^{9}$ However, whether sevoflurane interferes with the miRNA of lung 
cancer cells and suppresses lung cancer cells is unknown yet. Therefore, we hypothesized that sevoflurane affects the miRNAs that regulate A549 cells.

\section{Materials and methods}

\section{Cell line and cell culture}

A549, the human pulmonary adenocarcinoma cell line, was obtained from Shanghai R\&S Biotechnology Co., Ltd (Shanghai, People's Republic of China), and maintained in Roswell Park Memorial Institute-1640 supplemented with $10 \%$ fetal bovine serum, $100 \mu \mathrm{g} / \mathrm{mL}$ streptomycin, and $100 \mathrm{U} / \mathrm{mL}$ penicillin. The cells were incubated in $5 \% \mathrm{CO}_{2}$ humidified at $37^{\circ} \mathrm{C}$ for growth.

\section{A549 cell exposure to sevoflurane}

The cells were kept in a sealed container which was always moistened to $37^{\circ} \mathrm{C}$. Sevoflurane was carried by $0.5 \mathrm{~L} / \mathrm{min}$ mixture of $95 \%$ air and 5\% carbon dioxide through the volatilization tank (Drager, Lübeck, Germany). The concentration of anesthetic gas was monitored by a gas monitor (PM8050, Drager) at the outlet of the closed box, and the calibration of the volatile tank was adjusted to keep the concentration at $3 \%$. The sevoflurane group was treated for 30 minutes. The control group was also in the same incubator for the same culture, but was given a mixture of $95 \%$ air and $5 \%$ carbon dioxide, without sevoflurane.

\section{Quantitative real time polymerase chain reaction (qRT-PCR)}

Total RNA was extracted using Trizol reagent (Life Technologies, Carlsbad, CA, USA) for miRNA34a, miRNA155, miRNA146a, miRNA21, miRNA223, and miRNA221 analyses. For miRNA analysis, cDNA was synthesized using Bulge-Loop ${ }^{\mathrm{TM}}$ miRNA qRT-PCR Primer Set (All-in-One ${ }^{\mathrm{TM}}$ miRNA First-Strand cDNA Synthesis Kit; Gene Copoeia, Rockville, MD, USA) according to the manufacturer's instructions, normalized to that of U6 of the same RNA. Quantitative PCR was carried out using SYBR Premix Ex $\operatorname{Taq}^{\mathrm{TM}}$ (All-in-One ${ }^{\mathrm{TM}}$ miRNA qPCR Kit; GeneCopoeia, Inc., Rockville, MD, USA) according to the manufacturer's protocol. Relative expression was evaluated by comparative CT method and normalized to the expression of U6 small RNA. The target gene was quantified relative to the control gene and is expressed as fold change, calculated as $2^{-\Delta \Delta \mathrm{Ct}}$.

\section{Apoptosis analysis by annexin V/PI flow cytometry}

A549 cells were cultured in 12 -well plates $\left(1 \times 10^{5}\right.$ cells/well). After 3\% sevoflurane treatment for 30 minutes, cells were placed in $\mathrm{CO}_{2}$ incubator for an additional 2 days of culture. After that, the percentage of cell apoptosis was detected by flow cytometry analysis using an Annexin V-FITC Apoptosis Kit (Sungene Biotech Co., Ltd, Tianjin, People's Republic of China). Cells were washed twice with cold PBS, and resuspended in $400 \mu \mathrm{L}$ with $1 \times$ binding buffer at a concentration of $1 \times 10^{6}$ cells $/ \mathrm{mL}$. This binding buffer was supplemented with $5 \mu \mathrm{L}$ of annexin $\mathrm{V}$-FITC and incubated at room temperature in the dark for 15 minutes. Ten microliter of PI was then added and incubated at $4^{\circ} \mathrm{C}$ in the dark for 5 minutes. Cells were analyzed by a flow cytometer (BD FASAria Cell Sorter, BD Biosciences, Franklin Lakes, NJ, USA) within 1 hour.

\section{Statistical analysis}

Statistical analysis was performed using SPSS software 13.0 (SPSS Inc., Chicago, IL, USA). Values are expressed as the means $\pm \mathrm{SD}$. The significance of between-group differences was assessed using analysis of variance followed by Dunnett's test. $P$-values $<0.05$ were considered to indicate statistically significant differences.

\section{Results}

\section{Sevoflurane promotes apoptosis of A549 cells}

To observe the effect of sevoflurane on the apoptosis of A549 cells, we analyzed the cells using flow cytometry. As shown in Figure 1, 3\% sevoflurane was able to significantly decrease the number of A549 cells compared with control group, and apoptosis rate increased significantly $(P<0.05)$.

\section{Expression of miRNA}

qRT-PCR analysis showed that all 6 miRNAs changed. Relative expression ratios of miRNAs compared to the control group are presented in Figure 2. In the sevoflurane group, miR-21, miR-146a, miR-221, and miR-223 showed marked increases $(P<0.05)$. Compared to the control group, the expression of miR-34a and miR-155 decreased significantly in the sevoflurane group $(P<0.05)$.

\section{Discussion}

For NSCLC, the overall 5-year survival rate remains poor. ${ }^{10}$ Surgery is an effective method for the treatment of NSCLC. Sevoflurane was synthesized in the early 1970s, but was not released for clinical use until the early 1990s. It has been accepted worldwide as a safe and reliable anesthetic agent for clinical practice in various settings. Sevoflurane is a colorless, volatile, and nonflammable liquid with a characteristic smell. During sevoflurane anesthesia, bronchi, pulmonary alveoli, and tumor are directly exposed to sevoflurane. 

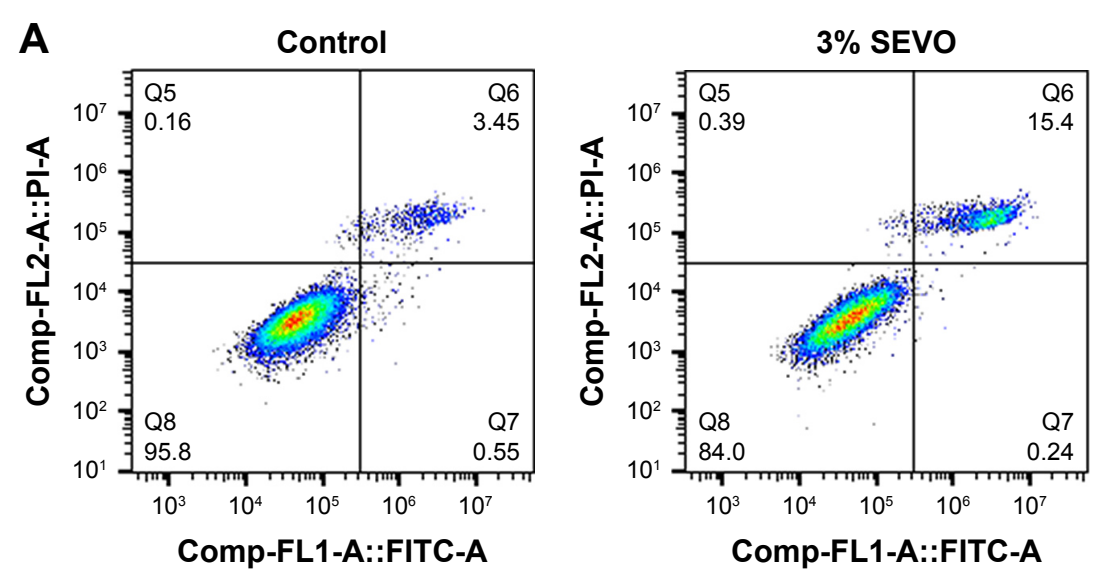

B

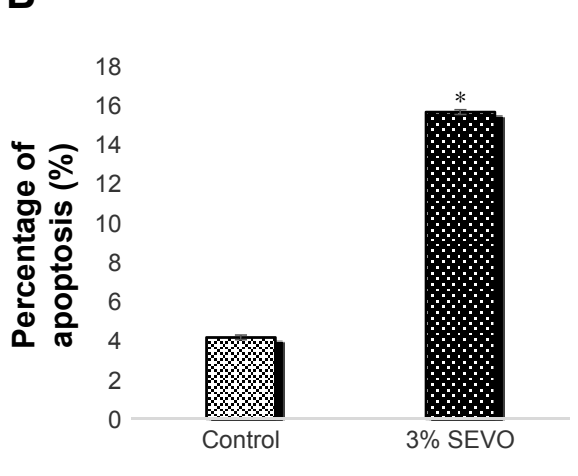

Figure I Effect of sevoflurane on apoptosis of A549 cells.

Notes: (A) A549 cells were treated with $3 \%$ sevoflurane for 30 minutes. Apoptotic percentage was analyzed by Annexin V/PI staining. (B) The bars represent the percentage of apoptotic A549 cells. Data are shown as mean \pm SD. *Indicates a statistically significant difference $(P<0.05)$.

Abbreviations: Comp, compensation; PI, propidium iodide; SEVO, sevoflurane group.
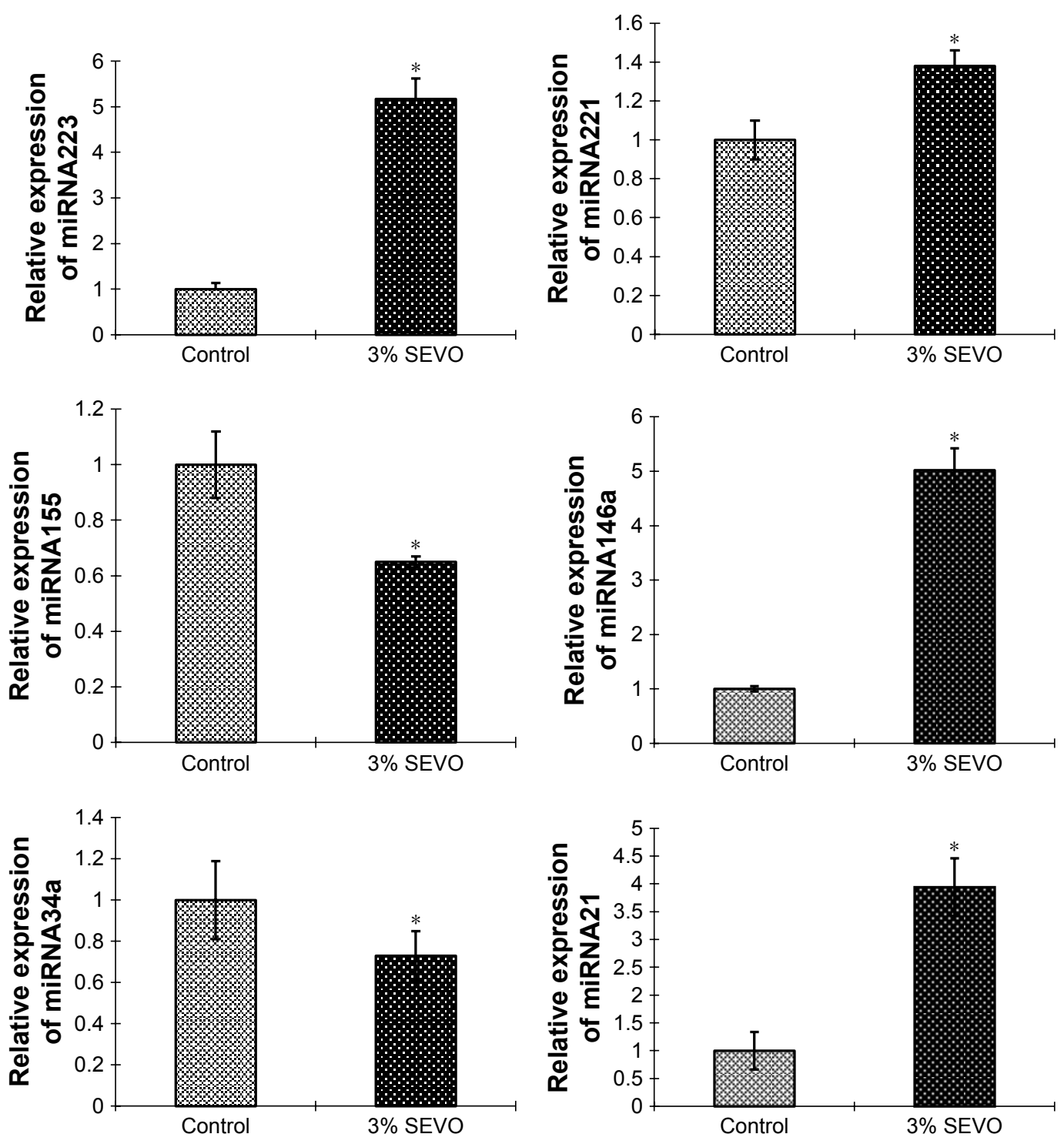

Figure 2 Effect of sevoflurane on the expression of miRNA in A549 cell.

Notes: Cells were exposed to $3 \%$ sevoflurane for 30 minutes, and the relative expressions of miRNA223, 22I, I55, I46, 34, and 21 were evaluated by qRT-PCR. Data are shown as the mean $\pm S D$. *Indicates a statistically significant difference $(P<0.05)$.

Abbreviations: qRT-PCR, quantitative real time polymerase chain reaction; SEVO, sevoflurane group. 
Sevoflurane has some protective effects on the respiratory system, provides bronchodilation, and attenuates bronchial smooth muscle constriction by histamine or acetylcholine and can be safely used in patients with asthma. Recent studies have found that $4 \%$ sevoflurane can modulate the expression of mRNAs and miRNAs in rat lungs, and then attenuate the toxic effects associated with lipopolysaccharide stimulation. The aim of our study was to elucidate the effect of sevoflurane on the miRNAs of lung cancer cells. We pretreated A549 cells for 30 minutes to simulate the clinical anesthesia setting. It has been confirmed that surgical operation can enhance the invasion and migration potential of cancer cells, thus improving its ability to spread during perioperative period. Cancer is marked by 6 hallmarks, one of which is resisting cell death. ${ }^{11}$

Our study found that $3 \%$ sevoflurane-pretreated A549 cells, for a duration of 30 minutes, that is, before surgery, caused an increase in the rate of cancer cell apoptosis, which greatly reduced the risk of cancer cell metastasis in the operation and increased the postoperative survival rate of the patients, which is similar to results of previous studies on sevoflurane..$^{12,13}$

Because of their wide variety of targets, miRNAs have been found to affect numerous developmental processes within cells including hematopoietic lineage differentiation, immunity, inflammation, and tumorigenesis. miRNAs in lung cancer cells include two major categories: oncogenic miRNAs and suppressive miRNAs. We selected three types of tumor suppressive miRNAs (miR-21, miR-221, and miR-155) and three oncogenic miRNAs (miR-146a, miR-223, and miR-34a), and they are all related to the apoptosis of cancer cells.

Some studies have shown that miR-155 upregulates Mxd1/Mad1, a network of basic helix-loop-helix leucine zipper transcription factors which mediate cellular apoptosis, through regulating BCL6. In this way, miR155 leads to the resistance of cell death and enables replicative immortality. ${ }^{14}$ Jeon et a ${ }^{15}$ observed that the $r s 2910164 C N G$ in pre-miR146a may contribute to genetic susceptibility to lung cancer. ${ }^{16}$ miR-223 functions as a tumor suppressor, which may finetune the activity of the IGF-1R pathway in lung cancer. ${ }^{17}$ These miRNAs are all associated with apoptosis of lung cancer cells. Our study found that $3 \%$ of sevoflurane preconditioning for 30 minutes did play a positive role, ie, increased the apoptosis rate of cancer cells, and that the three miRNAs (miRNA155, 146a, and 223) changed. Patients receiving sevoflurane pretreatment before surgery can indeed reduce the risk of cancer cell proliferation and metastasis during surgery. Although many documents ${ }^{14-17}$ suggest that these miRNA can regulate the apoptosis of lung cancer cells in a variety of ways, further study is needed on whether sevoflurane can increase apoptosis through these miRNA.
Chakraborty found that high expression of miR-34a in A549 and H1299 cells in NSCLC cells could significantly inhibit the expression of Bcl-2. ${ }^{18}$ Research has shown that miR-21 drives tumorigenesis through inhibition of negative regulators of the Ras/MEK/ERK pathway and inhibition of apoptosis. ${ }^{19}$ Garofalo et $\mathrm{al}^{20}$ reported that additional targets of miRNAs 221, such as PETN/TIMP $3^{21}$ and PUMA (also known as Bcl-2 binding component 3), ${ }^{22}$ seem to mediate TRAIL resistance, migration, and invasiveness, thus correlating with the frequent overexpression of these miRNAs in epithelial cancers, including lung cancers. ${ }^{23}$ However, after the treatment of A549 cells with 3\% sevoflurane, the changes of miRNAs $(34 a, 221,21)$ were different from what we expected, and from the previous experience on the impact of these miRNAs on cancer cells, the result should be the increase of cancer cells, but our result is that the apoptosis of cancer cells is increasing. Therefore, from our results, $3 \%$ sevoflurane-pretreated A549 cells can indeed change the miRNAs in cancer cells and increase the apoptosis of cancer cells. Although these miRNAs are related to the regulation of cancer cell apoptosis, the effects of sevoflurane on miRNAs seem to be irregular, that is to say, sevoflurane appears to randomly alter those miRNAs that regulate apoptosis, but the final result is the increase of cancer cell apoptosis. Of course, the number of miRNAs we studied was not enough to fully explain this phenomenon. More miRNAs need to be studied. It is necessary to further study whether sevoflurane can increase the apoptosis of cancer cells through the regulation of miRNAs, or assess if it just disrupts the miRNAs in A549 cells.

In conclusion, the results from our study revealed that $3 \%$ sevoflurane pretreatment of A549 cells for 30 minutes can change several kinds of apoptosis-related miRNAs, increase the apoptosis rate of lung cancer cells, and reduce the number of cancer cells.

\section{Disclosure}

The authors report no conflicts of interest in this work.

\section{References}

1. Jemal A, Siegel R, Xu J, Ward E. Cancer statistics, 2010. CA Cancer J Clin. 2010;60(5):277-300.

2. Coffey JC, Wang JH, Smith MJ, Bouchier-Hayes D, Cotter TG, Redmond HP. Excisional surgery for cancer cure: therapy at a cost. Lancet Oncol. 2003;4(12):760-768.

3. Snyder GL, Greenberg S. Effect of anaesthetic technique and other perioperative factors on cancer recurrence. Br J Anaesth. 2010;105(2): 106-115.

4. Brown BR Jr, Frink EJ. The safety of sevoflurane in humans. Anesthesiology. 1993;79:201-202.

5. Kvolik S, Dobrosevic B, Marczi S, Prlic L, Glavas-Obrovac L. Different apoptosis ratios and gene expressions in two human cell lines after sevoflurane anaesthesia. Acta Anaesthesiol Scand. 2009;53(9):1192-1199. 
6. Liang H, Gu M, Yang C, Wang H, Wen X, Zhou Q. Sevoflurane inhibits invasion and migration of lung cancer cells by inactivating the p38 MAPK signaling pathway. J Anesth. 2012;26(3):381-392.

7. Dai R, Ahmed SA. MicroRNA, a new paradigm for understanding immunoregulation, inflammation, and autoimmune diseases. Transl Res. 2011;157(4):163-179.

8. Chen X, Hu Z, Wang W, et al. Identification of ten serum microRNAs from a genome-wide serum microRNA expression profile as novel noninvasive biomarkers for nonsmall cell lung cancer diagnosis. Int J Cancer. 2012;130(7):1620-1628.

9. Tanaka S, Ishikawa M, Arai M, et al. Changes in microRNA expression in rat lungs caused by sevoflurane anesthesia: A TaqMan ${ }^{\circledR}$ low-density array study. Biomed Res. 2012;33(5):255-263.

10. Ludwig C, Stoelben E, Olschewski M, Hasse J. Comparison of morbidity, 30-day mortality, and long-term survival after pneumonectomy and sleeve lobectomy for non-small cell lung carcinoma. Ann Thorac Surg. 2005;79(3):968-973.

11. Lockshin RA, Zakeri Z. Programmed cell death and apoptosis: origins of the theory. Nat Rev Mol Cell Biol. 2001;2(7):545-550.

12. Goto G, Hori Y, Ishikawa M, Tanaka S, Sakamoto A. Changes in the gene expression levels of microRNAs in the rat hippocampus by sevoflurane and propofol anesthesia. Mol Med Rep. 2014;9(5):1715-1722.

13. Liang H, Wang HB, Liu HZ, Wen XJ, Zhou QL, Yang CX. The effects of combined treatment with sevoflurane and cisplatin on growth and invasion of human adenocarcinoma cell line A549. Biomed Pharmacother. 2013;67(6):503-509.

14. Higgs G, Slack F. The multiple roles of microRNA-155 in oncogenesis. J Clin Bioinforma. 2013;3(1):17.
15. Jeon HS, Lee YH, Lee SY, et al. A common polymorphism in premicroRNA-146a is associated with lung cancer risk in a Korean population. Gene. 2014;534(1):66-71.

16. Cornett AL, Lutz CS. Regulation of COX-2 expression by miR-146a in lung cancer cells. RNA. 2014;20(9):1419-1430.

17. Nian W, Ao X, Wu Y, et al. miR-223 functions as a potent tumor suppressor of the Lewis lung carcinoma cell line by targeting insulin-like growth factor-1 receptor and cyclin-dependent kinase 2. Oncol Lett. 2013; 6(2):359-366.

18. Chakraborty S, Mazumdar M, Mukherjee S, et al. Restoration of p53/ miR-34a regulatory axis decreases survival advantage and ensures Bax-dependent apoptosis of non-small cell lung carcinoma cells. FEBS Lett. 2014;588(4):549-559.

19. Hatley ME, Patrick DM, Garcia MR, et al. Modulation of K-Rasdependent lung tumorigenesis by MicroRNA-21. Cancer Cell. 2010; 18(3):282-293.

20. Garofalo M, di Leva G, Romano G, et al. miR-221\&222 regulate TRAIL resistance and enhance tumorigenicity through PTEN and TIMP3 downregulation. Cancer Cell. 2009;16(6):498-509.

21. Garofalo M, Quintavalle C, Romano G, Croce CM, Condorelli G. miR221/222 in cancer: their role in tumor progression and response to therapy. Curr Mol Med. 2012;12(1):27-33.

22. Zhang C, Zhang J, Zhang A, et al. PUMA is a novel target of miR-221/222 in human epithelial cancers. Int J Oncol. 2010;37(6):1621-1626.

23. Galardi S, Mercatelli N, Giorda E, et al. miR-221 and miR-222 expression affects the proliferation potential of human prostate carcinoma cell lines by targeting p27Kip1. J Biol Chem. 2007;282(32):23716-23724.
OncoTargets and Therapy

\section{Publish your work in this journal}

OncoTargets and Therapy is an international, peer-reviewed, open access journal focusing on the pathological basis of all cancers, potential targets for therapy and treatment protocols employed to improve the management of cancer patients. The journal also focuses on the impact of management programs and new therapeutic agents and protocols on

\section{Dovepress}

patient perspectives such as quality of life, adherence and satisfaction. The manuscript management system is completely online and includes a very quick and fair peer-review system, which is all easy to use. Visit http://www.dovepress.com/testimonials.php to read real quotes from published authors. 